\title{
The Mediating Role of Job Embeddedness Fit: Perceived Job Characteristics and Turnover Intention in the Services Sector
}

\author{
Qaisar Iqbal, Noor Hazlina Ahmed, Sohail Akhtar*
}

\begin{abstract}
Organizations able to retain their human resources have an advantage over their competitors. Employee turnover adversely affects the stability of the workforce and carries the cost of having to hire and train new personnel. Employee retention is, therefore, a priority for senior management. This study explores the mediating impact of employee fit in terms of organizational job embeddedness on the relationship between job characteristics and employees' intention to quit. Based on a sample of 375 employees working in a private commercial bank in Pakistan, we find that job identity, job significance and task variety have a significant negative effect on intention to quit. Job variety has the greatest impact on turnover intention. Organizational job embeddedness fit mediates the relationship between two of three job characteristics - job identity and significance - and turnover intention, but not the latter's relationship with perceived task variety. Thus, organizational job embeddedness fit mediates the relationship between overall job characteristics and turnover intention.
\end{abstract}

Keywords: job identity, job significance, job characteristics, organizational job embeddedness fit, turnover intention.

JEL classification: M510, J22, J23, J62, J63.

\footnotetext{
* Qaisar Iqbal and Sohail Akhtar are PhD students at the School of Management at Universiti Sains Malaysia. Noor Hazlina Ahmed is a professor at the School of Management at Universiti Sains Malaysia.
} 